\title{
PLAYING AND CREATING AUDIENCES: MEDIA USERS-GENERATED CONTENT QUALITY ASSESSMENT
}

Internet is defined as highly democratic medium, which is growing at the result of media users' generated content. Theoretical insights of various authors regarding improvement of media users-generated content quality are discussed in the article. This problem reflects not only ever-changing media use models but is also related with fierce discussions on media regulation issue. Developing initiatives reveal attempts to deal with media content quality issues and encourage more frequent discussions of how it should be done and how it could affect the modes of interaction between media companies and media users in the future.

\section{Keywords: media usage, media content, media regulation, quality assessment}

Rapid internet development in the last several decades radically changed media use models. Today, it is impossible to talk about media content without analyzing audience-generated content problems, because audience activity is one of the crucial reasons of media landscape changes.

Investigating transformation of media usage patterns it is obvious that traditional media contents created in technical, economic, political and information environments no longer exist and the audience activity is one of the main reasons of the media landscape transformations. On the one hand, the lack of censorship lets treat the internet as a very democratic space without any existing editorial board or other control mechanism. Media users generated content is very valuable for its high quality, especially in the niche media, which bring together professionals and expert communities. Essence of the new media is a model based on cooperation, teamwork and sharing of information. Therefore, the audience transformation trends influence a blurring distance among the professional media creators and the media users. But on the other hand, virtually there are no barriers to place the low-quality messages (shoddy comments, misleading information, etc.) into the public space. The quality of the media content is being recognized as a problem both as the scholars, as well the media companies worldwide. For example, such cases, as the filmed images of rape or murder uploaded on Youtube, show that some regulatory mechanisms are needed. What criteria define highquality and low-quality media content? What might be done for the media content improvement?

The purpose of this paper is to discuss the emerging initiatives on the regulatory of the media users-generated content. The European Union's Audiovisual Media Service Directive or Google's Public Policy Blog reveal the positive initiatives both the political forces and media companies in setting regulations on broadcasting and for content viewed on other platforms, like the internet or mobile phones.

\section{Epoch of Freedom and Dilettantism: Activity as a Play and Playing Audiences}

Majority of post-modernism theoreticians when discussing in their writings social-economic transformations of the late-20th century mentioned the new era, new times, new epoch, new media were seen as the axis of which. Thus the new-born phenomenon and its influenced epoch changes were given distinctive ideological load. New media were named as the major factor in explaining on-going global information and communication change processes. New media marked new stage of media development which is associated with the 
birth of digital technologies, but many representatives of academic world note that not new technologies play the vital role but rather their induced changing communication models and new information presentation and receipt modes (Breen, 2007; Kyong Chun, 2008).

New media have radically transformed a system of media content organisation and distribution, as well interaction among the media and their audiences. Digitisation and the media convergence processes generate new practices and media usage patterns. Audiences live in the media-saturated environment and their choices have completely different nature and logic that were typically characterized in the era of traditional media. Moreover, new media and pop culture suggest various practices related with consumption-related activities and daily living of audiences. On the back of it, the new phenomenon like social network websites created the preconditions to emerge a wide open space for self-realization and self-actualization of media users. The new media environment is recasting the notion of audience for covering a wide range and multifaceted activities of media users. Playful nature today is acquired by any serious business activity, since the aspect of individuality appears in it. Penetration of play into serious business fields is taking plays nowadays. Even business world, market sectors became closely interrelated with a play, certain tension which is characteristic to any playful action. But the epoch of freedom is followed by the period of dilettantes (Хренов, 2005: p. 25.). Human being finds himself/herself in uncommon elements and activity fields. He/she is searching, making mistakes and gets disappointed often. New media practices integrate into all daily social activities, but are mainly oriented to leisure time. It is time when many people become experts. Individuals update their profiles, change and upload photographs, make lists of favourite films, TV shows or music. They play games, chat, watch other people's comments about their favourite games, choose clothes and other products, which help to express their individuality (Willett, 2008). Time spent with media is associated with creation, pleasures, and mainly, freedom. New media as democratic media induce an epoch of freedom when all aspects of human activity assume a playful nature even though the professional spheres are associated with the game.

In the new multimedia environment the range of activities of modern audiences has become highly extensive and multi spectral, therefore the whole range of new roles performed by modern media users can be discussed. New modes of audience and media interaction are testified also by much bigger number of terms than before used to define audience members and their new roles: user, customer, player, producer, visitor, gifter, fan, friend, voyeur, learner, and participant (Davis - Michelle, 2011: p. 560.). Furthermore, media user is media creator, consumer and content distributor at the same time, while media users-generated content and social media transform modern media system. One of the crucial changes marking modern epoch is media users'-generated content development.

The development of new media depends not only on media companies but as well on media users because of their media competence, creativity and initiatives. Therefore, the most meaningful concepts should be recognized those which indicate the creative potential of audiences. In addition, the media user can be defined as a creator, a user and a distributor of the media-generated content at the same time.

\section{Media Users Generated Content Quality Assessment}

Over the past five years, the media users-generated content (UGC) has become one of the most dominant forms of media content in the world and connections to social networks have enormous potential for communication, information exchange, advertising, business development, etc.

User-friendly environment, low cost of media content control tools, simple content upload tools determine fast growth of media content forms and scope. Such social website platforms, like Facebook, Twitter, YouTube or Wikipedia become inseparable part of many people's daily life, which changes trends of communication processes S. Livingstone emphasizes that if before people grew up watching the same television programmes and dramas, so modern generations unite into social networks and their identity is shaped by virtual communities (Livingstone, 2010). Participatory, or also called Gaming, Do-it-yourself, etc. culture development could explain fast development of social media and growth media users-generated content scope related with them. Media users-generated content consists of various media formats: social networking, image and video sharing, wikis, blogs, online discussion forums, social Q\&A sites and products reviews. According to G. Lastowska, various information forms which can be presented to audience can be named as content, and in broad meaning they synonymously mean creative work (Lastowska, 2010). A. Bruns gives 4 main users generated content characteristics:

- a shift from creation-dedicated individuals or teams of them to collaboration and continued 
content supplement in pursuit of its further improvement,

- changing roles: content creators become participants, while their range varies from amateurs to professionals,

- artefacts are no longer products in traditional sense: they are always unfinished and subject to on-going supplement - evolutionary and repeating model,

- content generation is based on free collaboration regime rather than on obligations (Bruns, 2007).

Modern Do-It-Yourself culture type uplifts and even romanticizes a modern user to some extent, but it is useful to conduct a more comprehensive discussion of the problems of media users-generated content quality and factors affecting them. On one hand, substantial part of media content is useful and of good quality, in particular in niche media, which unite professional and expert communities interested in exchanging ideas and knowledge. Notices in digital environment are not complete, they are open to adjustment and supplement. It is the essence of modern operation of interactive media, which is based on collaboration, team work and information exchange. Beside, news ports increasingly use messages of media users, often sent from the epicenter of events. On the other hand, public space is practically open for low quality messages to enter (spam, information degrading human dignity, valueless comments, misleading messages, etc.). Notwithstanding the opportunity given by internet to the users to carry out their activities and share their ideas much easier, intellectual property is subjected to increasing number of violations. Global nature of internet determines the location of intellectual property violations in electronic medium not to be limited to one country but rather crossing the state borders. This makes the search for adequate solutions for improvement of media content quality even much harder.

This time leaving the problem of information quantity growing in geometrical progression aside, the most relevant problems regarding quality of media usersgenerated content must be two: intellectual property violations, information reliability and ethical problems of information. According to M. Kiškis, basically, intellectual property violations in electronic medium should be qualified same as conventional intellectual property violations, and in some cases electronic violations should be qualifies even as more dangerous (Kiškis, 2011). Many countries have the above-mentioned offences included into their criminal and administrative codes. Attempts are made to tackle this type of offences by legal means, while content quality issue urges search for technological solutions. Major technical protection modes include filtering, blocking and content control. Technological possibilities enable internet control, which is free and global by its very nature, control of internet in various levels, but a question arises, what legal control is and to what extent it can be applied. In this context, one of the most pressing issues is the question, who must have the duty to exert control and whether such control does not infringe fundamental human rights and freedoms.

Another problem that is more difficult to handle is inaccurate and unreliable information spread by the media users themselves. Both in daily life context and in professional life, users search for information which would be authentic, reliable, provided by experts of the field in question, valid. From the massive amount of online information media users try to find the most suitable, most extensive content satisfying their needs. Scientific articles are reviewed before publishing them online, while all the other materials usually are placed without checking, they are full of mistakes and inaccuracies. Yahoo! research discovered that major part of users-generated information is boring and dull that nobody reads it, save for information prepared by marketing experts trying to make information useful, interesting and attractive (Yahoo! Advertising Solutions, 2013). As it is noticed by M. Anderka et al., that researched Wikipedia content problems, the community of virtual encyclopedia authors is highly heterogeneous, covering people of different educational background, age, culture, language abilities and experience, i.e. totally different to paper encyclopedias which were compiled exclusively by experts (Anderka et al., 2012). This can obviously explain arising problems of media content quality and, according to G. Lastowska, can be linked with respective behaviour models. Majority of people creating media content do not receive any material remuneration for their activities, but they are motivated by the possibility of self-expression, playful nature of this interactive activity, which at the same allows to become known to a wider circle of people and establish more social contacts, which are turning into important social capital in modern society.

\section{Debates: Media Regulation vs Self-Regulation}

Media users themselves have limited possibilities for organising media content quality control, but necessity for regulatory instruments is recognised all over the world. 
When analyzing debates between media regulatory supporters and opponents, complexity of the problem must be considered - role of economic, social, cultural motives when dealing with these problems. Media regulation supporters first of all highlight the problems of infringement of intellectual property rights and content quality (cheap content - costs cheap). Besides, they argue that recently human right to privacy has been in particular brutally infringed, and this problem needs to be dealt with even if some privileges had to be taken away from media companies (O'Neill, 2011).

While supporters of media self-regulation emphasize supremacy of freedom and democracy, which from the very beginning of new media operation were named as their main characteristic feature. Argument that Internet secures the right to information for every single media user cannot be denied. Websites created by nobody else but media users contain information about unethical activities or low quality products of large business corporations, for example, that expensive branded cosmetics is stuffed with chemicals, while have of ingredients of advertised organic toothpaste were oil-based products. A. Puddephatt highlights also human right to self-expression and free expression of one's opinion, which are obviously secured by modern media (Puddephatt, 2011). Besides, it is noted that media themselves are capable of assessing and controlling their distributed information. But based on the conducted research P. Organisiciak and others state that with a small number of exceptions, majority of content websites do not provide their users with content control possibility (Organisiciak et al., 2010). J. Van Dijck referring to Galloway also states that even if content is named as generated by users, it does not mean that users are in full control of the product they created, since technological and social protocols are controlled by Internet companies (Van Dijck, 2009:51). Furthermore, it is stated that media companies not only fail to exert active filtering of improper content and provide possibilities of free expression of word to media users, thus brutally infringing other people's rights and dignity, but they also use information as a weapon in the battle for influence and power. According to U. Ulfkotte, freedom of information has been gradually turning into the truth of clients, when it is not the truth itself that matters but rather something that is considered by majority as truth (Ulfkotte, 2013). Evidently, economic motives operate in this perspective. M. Ingram is right saying that such giant companies, like Amazon, Yelp, Facebook, YouTube, Twitter and many others are growing and expanding only thanks to media users' involvement and collaboration, therefore In- ternet companies are closely related with their users (Ingram, 2010). G. Lastowska also mentions that the past essence of a business model of media companies lying in sale of professionals' generated information is undergoing transformation into design and distribution of tools enabling media users to create content (Lastowska, 2010). Therefore, the author names these phenomena not only as cultural revolution but also as today's business model of media companies. Majority of countries are familiar with necessity for media regulatory mechanism introduction, but this process causes lots of questions.

In modern stage of media development the most important thing is that destructive communication influence problems have fallen into the focus of attention of both scholars and practitioners and various solutions of these problems are considered and discussed at global scale.

\section{Initiatives on Incentivizing of High Quality of Media Users Generated Content}

Solutions of problems cover various issues, starting from technological aspects and finishing with formulation of political institutions' directives. Media companies are working on installation of filtering systems, international expert groups are developing recommendations on effective use of virtual resources, media users create web pages, on which their comments are placed and rating systems are organised to assess the quality of content presented.

Going back to content quality assessments, it should be noted that in order to be able to asses media content quality, certain uniform system of standards is needed. Thus, one of the most urgent issues today is - based on which criteria high-quality and low-quality content could be defined, on the basis of which content improvement initiatives could developed. Usually classification system, clear criteria and standards are used to assess quality. P. Posch and $\mathrm{H}$. Altrichter notice that quality is a relative term, which can be understood differently by different groups (Posch - Altrichter, 1997, in: Altrichter, 1999). It means that every author has his/ her own purposes, system of values, amount of knowledge and skills, attitude to quality. Various theories and assessment methods are available on virtual space. Beside, assessment process closely depends on understanding of the role of the assessor. Assessor can also be limited by his/her own experience, knowledge, professional background. (Attwell, 2006). Because of two different users' positions, quality assessment criteria 
can be defined differently depending on what should be considered as the most important aspect of media operation: commercial success, big number of visitors or accuracy of contained information. The European experience is outlined by the directives of the European Union institutions.

European Commission states in its issued communique that activity of the media remains being the key prerequisite for European citizens to gain better understanding of the world and to participate in democracy and cultural life, while media literacy can substantially contribute to achievement of the goals set by the Lisbon European Council set in 2000 for the European Union, which is important for development of more competitive knowledge economy (Communication from The Commission to The European Parliament, The Council, The European Economic and Social Committee and The Committee of The Regions No COM (2007) 833:2). The Commission in its recommendations given to the European Parliament and European Union Member States note that users media literacy needs to be developed, which contains at least three tasks:

- giving young audiences tools to develop a critical approach to commercial communication, enabling them to make informed choices,

- raising awareness and knowledge among all interested parties about self- and co-regulatory measures and mechanisms and about the development and implementation of codes of conduct,

- encouraging public/private financing in this area with adequate transparency (Communication No $\operatorname{COM}(2007)$ 833:6).

The communique of the Commission shows that consensus of all countries concerned and equal involvement in creation of uniform democratic and ethical media space are sought. European citizens' awareness development remains priority aspect in the European Parliament's directives, by implementing European audio-visual policy (European Parliament's resolution on Television Without Frontiers of 6 September 2005 (89/552/EEC). United Nations Educational, Scientific and Cultural Organisation (UNESCO) also supports the position that media companies, libraries, archives, museums must contribute to citizens' media competences, not only among urban but also among rural communities and of socially less protected group members (Scott, 2009). UNESCO's goal is that various broadcasters groups, publishing associations and other organisations at the global scale would commit themselves to observe common principles of media lit- eracy and ethics, while prepared guidelines highlight the necessity of close collaboration between media organisations and media users in jointly dealing with content improvement issues, because only various ideas and coordination of different positions would enable the best outcome. In implementing this mission, substantial role is placed on highly qualified professionals in developing methodical guidelines for both media companies and media users. In this context, content assessment recommendations given by educational sector experts in selecting sources are worth mentioning. A lot of attention in them is focused on identifying elements determining the content value: authorship, links presented by the author to respective institutions, text update date, provided sources, etc. In one of the European Commission's initiated projects The QuatroPlus, pursuing media content quality it has been defined positive and negative media content characteristics. The following characteristics to be evaluated as positive were named:

- valuable consulting content,

- content with clear educational value,

- promoted humanistic values,

- environmental issues discussed,

- supporting children's rights,

- entertainment and games.

Negative characteristics included the following:

- user's generated content (vague authorship),

- unreliability of information,

- violence propagation,

- personal data protection breaches,

- propagation of anorexia, drugs, illegal activities,

- vulgar language,

- hidden advertising,

- instigation of hatred, racism xenophobia (The QuatroPlus Project, 2009).

When looking from the audience studies perspective, it should be answered the relevant question: what strategies are followed by media users themselves when choosing media content. Researches conducted in various countries show on which features media users judge the quality of online information content. Summarizing various sources Metzger distinguishes such remarkable factors in evaluation processes of online resources for media users: presence of date stamp showing information is current, source citations, citations to scientific data or references, author identification, author qualifications and credentials, presence of contact information, absence of advertising, presence of privacy and security policies, certifications or 
seals from trusted third parties, professional, attractive, and consistent page design, including graphics, logos, color schemes, easy navigation, well-organized site, sponsorship by of external links to reputable organizations, notification/presence of editorial review process or board, absence of typographical errors and broken links, professional-quality and clear writing, download speed, etc. (Metzger, 2007: p. 2082.).

If the media content problems have been resolving through reglamentation of quality, the other sore point - the privacy infringement cases. The hot topic is not new and exists not only in the virtual space. Some kind of that could be seen in the traditional media, especially on the press in the announcements of the misleading or very private information about celebrities. Even though such tendencies are condemn by the public at large the tabloids argument is always the same that the audience is needed for such information. Analogical processes go on now in the virtual space when the legal disputes are launched against the internet commentators for their insulting homophobic comments. In this case some kind of the educative effect can be presumptive for all active commentators. But who would effect the authors for their video or texts propagating violence and destruction, especially harmful for young people and emotionally unstable persons? Such video as shooted in Asia countries with the rape images and distributed over the video share websites induce the requirements for the stricter media control. Therefore, such tendencies are needed deeper analysis of the situation.

Summing up the above it should be noted that the most valuable insights of the scholars can be treated those which are dealing the following questions: what should be done in encouraging the media users to generate qualitative and valuable content? How to raise the quality of amateur content? How can users contribute to assessing quality content? Arguments in the going discussions underline necessity of the collaboration by all acting parties in the organisation and distribution of media content. As U. Hasebrink noticed, media users can participate in the regulatory processes as well and in the discourse on media quality (in general) and media diversity (in particular), because only users can define the best kind of media could serve the public (Hasebrink, 2011).

Contemporary trends show that the media users have been the key driving force in the today's media development. Experience how to deal with the negative manifestations of them, even on the global scale, is not really abundant. Scientific literature draws attention to close relation between user-friendly media usability and growing amount of media user-generated content. After debates among the scholars about the shifting roles of media users in the recent media landscape the further step is the initiation of deeper analysis of the best practises and main factors in incentivizing of high quality of media user-generated content.

\section{Highlights and Future Perspectives}

Today, the main practices of combating illegal and harmful media content comprise legal and technological means. When analysing content control possibilities and observing examples of some countries, one can see that internet service providers have technical possibilities available for implementing any preventive media content filtering and monitoring. But any content censorship encounters the shortage of legal measures, since no agreement has been reached on what basis such censorship should be applied. Precondition for practical application of such measures is expressive definition of harmful, improper, inaccurate content criteria and responsibilities shared among media companies, content creators and distributors. Ongoing national law harmonisation with international law is creating the basis for explanation of virtual crimes and offences.

But it must be noted that one of the key activity directions in tackling these problems named in the EU communique include media users' education and their awareness raising. Practitioners and theoreticians should lead more active discussions in this direction in particular. Media literacy development is often oriented to youth critical thinking development, instead it should include also the issues of media users' ethics and responsibility. People must be able not only to use media technologies or know how to satisfy their information and communication needs, but they should also understand their, as media users' rights and duties. Development of understanding of irresponsible actions in virtual world should be an important preventive measure.

EU communiqué suggest awareness raising campaigns among mass media information actions, which would be carried out considering the best practice and experience of other countries, as well as partnership support among the main stakeholders (governmental authorities, press and mass media groups, IPT associations, consumer organisations, interested persons in the field of education) and promotion of their dialogue. Discussions among media theoreticians, practitioners and audience members, as media content co-authors, 
initiated in public space would allow to draw public attention to urgency of these problems and to search for common points in tackling media quality improvement problems. Increasing number of cases of private information leakage into public space and infringement of human rights shows the necessity for this kind of discussions. Media users must be aware not only of problems that may arise in virtual space but also of possible ways to deal with them. Suggested measures enable media users themselves to take active part in creation of quality virtual space and self-regulating mechanisms.

Scientists' mission in this whole context should be creation of awareness rising material and initiation of exchange experience.

\section{Conclusion}

The purpose of this article was to define the main problems related with the media users generated content.

Due to the declining profitability of traditional media, the business strategies have been transferring to the internet with the supreme focus to the social and niche media. Consumption of audiences is growing because of the media usability and adaptability for the media users to create and distribute their own content. In today's media stage of development, it should be noted that media usage is closely related with the individuals' daily routine and becomes more diverse than in the era of mass communication. Time devoted for media usage is longer than ever before. Moreover, virtual space is open not only for the individuals, but also to the legal entities, the public authorities and so on. They act as tantamount parties as the authors alongside with the media organisations in the content creation processes. The quality of media content is under discussions not only among the professionals which emphasize the insalubrious effect of the users generated content as value shifting and depreciatory of the professional information. Activities of all acting agents of the media sector are related to the further media propositions. Therefore, in was stated in this article that all parties should participate in shaping media policy. It was proposed that the scientific discussions as the initiatives of the media organizations, the political institutions, the media users are on the stage when the collaborative leads are needed.

The scientific insights analyzed in this article serve as the guidelines for further composing of the theoretical and empirical research background focused on incentivizing of high quality of the media users generated content.

\section{References}

Altrichter, H. (1999): Quality Features in Action Research Strategy. Change: Transformation in Education, Vol. 1, No. 2.

Anderka, M. - Stein, B. - Lipka, N. (2012): Predicting Quality Flaws in User-generated Content: The Case of Wikipedia. http://www.uni-weimar.de/medien/webis/ publications/papers/stein_2012i.pdf, Retreived: 13 Oct, 2013

Attwell, G. (ed.) (2006): Evaluating e-learning: A guide to the evaluation of e-learning. Evaluate Europe Handbook Series Vol.2, http://www.pontydysgu.org/wp-content/ uploads/2007/11/eva_europe_vol2_prefinal.pdf, Retrieved: March 20, 2013.

Breen, M.J. (2007): Mass Media and New Media Technologies. Media studies: key issues \& debates. ed. Devereux, E. London: SAGE Publications

Commission of the European Communities (2007): Communication from The Commission to The European Parliament, The Council, The European Economic and Social Committee and The Committee of The Regions: A European approach to media literacy in the digital environment

Davis, Ch.-Michelle, C. (2011): Q Methodology in Audience Research: Bridging the Qualitative/Quantitative 'Divide"? Participations: Journal of Audience and Reception Studies, Vol. 8, No. 2: p. 559-593.

Eastin, M.S. - Daugherty, T. - Burns, N.M. (2010). Handbook of Research on Digital Media and Advertising: User Generated Content Consumption. New York: Hershey

Hasebrink, U. (2011): Giving the Audience a Voice: The Role of Research in Making Media Regulation More Responsive to the Needs of the Audience. Journal of Information Policy, Vol. 1, No. 1: p. 321-336.

Ingram, M. (2010): The Downside of User-Generated Content. BloombergBusinessweek. Technology. http:// www.businessweek.com/technology/content/mar2010/ tc20100325_944655.htm, Retrieved: 2 Apr, 2013.

Kiškis, M. (2011): Intelektinès nuosavybès teisinè apsauga elektronineje erdvèje. Vilnius: Mykolo Romerio universiteto Leidybos centras, 2011.

Криволап, A. (2011): Девальвация медиа-активизма: от «DIY» до «I Like». in: Международный журнал исследований культуры: научное электронное издание. http://www.culturalresearch.ru/ru/media/73devact, Retrived: 28 Apr, 2012

Chun, W.H.K. (2009): History of New Media. International Encyclopedia of Communication. http://www. communicationencyclopedia.com/public/tocnode?id =g9781405131995_chunk_g97814051319959_ss38-1, Retrieved: 20 Feb, 2009.

Kumar, K. (2005): From Post-Industrial to Post-Modern Society. Oxford: Blackwell Publishing. 253 p. ISBN 978-0-06311-85598 
Lastowska, G. (2010): User-Generated Content and Virtual Worlds. Vanderbilt J. of Entertainment and Tech. Law, Vol.10, No. 4, 893-917. http://www.jetlaw.org/wp-content/ journal-pdfs/Lastowka_FINAL.pdf, Retrieved: 1 Apr, 2013.

Livingstone, S. (2010): Youth Participation: What Have We Learne, What Shall We Ask? Keynote lecture, Digital Media \& Learning Conference, February 20, 2010. http://dmlcentral.net/sites/all/files/resource_files/ Digital_Media_and_Learning_conference_keynote_ Livingstone_final.pdf, Retrieved: 12 Oct, 2011.

Metzger, M.J. (2007): Making Sense of Credibility on the Web: Models for Evaluating Online Information and Recommendations for Future Research. Journal of the American Society For Information Science And Technology, Vol. 58, No.13: p. 2078-2091.

O'Neill, O. (2011): The Rights of Journalism and the Needs of Audiences. University of Oxford. Reuters Institute for the Study of Journalism. Reuters Memorial Lecture. http://reutersinstitute.politics.ox.ac.uk/fileadmin/ documents/presentations/The_Rights_of_Journalism_ and_Needs_of_Audiences.pdf, Retrieved:15 Mar, 2013

Organisiciak, P. - Reed, K. - Hibbert, A. (2010): Shortcuts and Dead Ends: Control Issues with Online User-Generated Content. University of Alberta. http://www.cais-acsi.ca/ proceedings/2010/CAIS080_OrganisiciakReedHibbert_ Final.pdf, Retrieved: 15 Mar, 2013
Puddephatt, A. (2011): The Importance of Self Regulation of the Media in upholding freedom of expression Communication and Information. UNESCO. http:// global-partners.co.uk/wp-content/uploads/Importanceof-slef-reg-English.pdf, Retrieved: 15 Mar, 2013

The QuatroPlus Project (2009): Project sponsored by the Safer Internet Unit of the European Commission to promote quality labelling. http://www.quatro-project. org/qualitylabels/who, Retrieved: 11 Oct, 2012

Ulfkotte, $U$. (2013): Taip meluoja žurnalistai. Vilnius: Mintis

Van Dijck, J. (2009): Users like you? Theorizing agency in user-generated content. Media Culture Society. Vol. 31, No. 1: p. 41-58.

Yahoo! Advertising Solutions (2013): Storytelling Across Paid, Owned, and Earned Media. http://advertising. yahoo.com/article/what\%E2\%80\%99s-your-story-. html, Retrieved: 10 Mar, 2013

Willett, R. (2008): Consumer Citizens Online: Structure, Agency, and Gender in Online Participation in Youth, Identity, and Digital Media edited by Buckingham, D. The John D. and Catherine T. MacArthur Foundation Series on Digital Media and Learning. Cambridge, MA: The MIT Press: p. 49-70.

Хренов, Николай А. (2005): “Человек играющий” в русской культуре. Санкт-Петербург. 608 р. ISBN 5-89329-753-9.

\section{T HE A U T H O R S O F T H IS IS S UE:}

Zsolt Varga, Ph.D. student, Budapest Corvinus University, Media Marketing Communications and Telecommunication Department; Nóra Nyirố, Ph.D., Account Director, OMD Hungary; Daiva Siudikiené, Ph.D. student, Vilnius University, Communication Faculty; Tamás Csordás, Ph.D. student, Assistant Research Fellow, Corvinus University of Budapest; Mirkó Gáti, Ph.D. student, Assistant Research Fellow, Corvinus University of Budapest; Angela Chang, Assistant Professor, Communication Department, University of Macau; Tamás Bokor, Ph.D., Assistant Professor, Corvinus University of Budapest; Dóra Horváth, Ph.D., corresponding author, Associate Professor, Corvinus University of Budapest; Ariel Mitev, Ph.D., Associate Professor, Corvinus University of Budapest; András Bauer, Ph.D., Associate Professor,Corvinus University of Budapest 